\title{
Association of eggs with dietary nutrient adequacy and cardiovascular risk factors in US adults
}

\author{
Melissa M Melough ${ }^{1}$, Sang-Jin Chung ${ }^{2}$, Maria Luz Fernandez ${ }^{1}$ and Ock K Chun ${ }^{1, *}$ \\ 'Department of Nutritional Sciences, University of Connecticut, 209 Roy E. Jones Building, 3624 Horsebarn Hill \\ Road, Storrs, CT 06269, USA: ${ }^{2}$ Department of Foods and Nutrition, Kookmin University, Seoul, Republic of Korea
}

Submitted 3 April 2018: Final revision received 19 December 2018: Accepted 10 January 2019: First published online 5 March 2019

\begin{abstract}
Objective: Whole eggs are rich sources of several micronutrients. However, it is not well known how egg consumption contributes to overall nutrient adequacy and how it may relate to CVD risk factors. Therefore, the present study aimed to determine how whole egg consumption contributes to nutrient intakes and to assess its association with CVD risk factors in US adults.

Design: Cross-sectional study.

Setting: The study was conducted using data from the National Health and Nutrition Examination Survey (NHANES) 2003-2012, a nationally representative survey of the US civilian population.

Participants: Adults who completed two dietary recalls and provided information on relevant sociodemographic factors were included in the study ( $n$ 21 845).

Results: Approximately $73 \%$ of adults were classified as whole egg consumers. Egg consumption was associated with greater intakes of protein, saturated fat, mono- and polyunsaturated fats, $\mathrm{Fe}, \mathrm{Zn}, \mathrm{Ca}$, Se, choline, and several other vitamins and minerals. Egg consumption was associated with a higher likelihood of meeting or exceeding recommendations for several micronutrients. Egg intake was positively associated with dietary cholesterol consumption, but not with serum total cholesterol (TC) when adjusted for multiple potential confounders. In multiple linear regression analyses, TAG, TAG:HDL-cholesterol and TC:HDLcholesterol were significantly lower with greater egg consumption. Egg consumption had no significant relationship with LDL-cholesterol or C-reactive protein, but was associated with higher BMI and waist circumference.

Conclusions: Whole eggs are important dietary contributors of many nutrients and had either beneficial or non-significant associations with most CVD risk biomarkers examined.
\end{abstract}

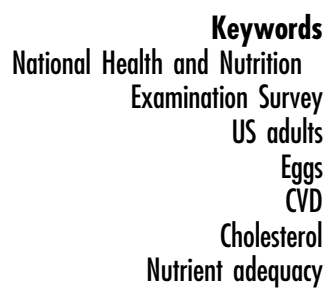

CVD is a public health crisis in the USA and is currently cited as an underlying cause of one out of every three deaths in the USA ${ }^{(1)}$. Diet is well recognized as a major lifestyle factor that can influence CVD risk, but public perceptions and scientific guidance regarding the most heart-healthy eating patterns has evolved over time. In particular, eggs have undergone major shifts in perceived suitability for a heart-healthy diet in recent decades. While eggs are good sources of high-quality protein and many key micronutrients including choline, carotenoids, Se, and vitamins A and D, eggs also contain roughly $200 \mathrm{mg}$ of cholesterol each, which has been flagged as a potential problem for those at risk for CVD since high blood cholesterol levels are an important risk factor for the disease $^{(2)}$.

The 2015-2020 Dietary Guidelines for Americans no longer include the $300 \mathrm{mg}$ recommended daily limit for dietary cholesterol from previous editions, but still advise Americans to 'eat as little dietary cholesterol as possible while consuming a healthy eating pattern'(3). Removal of this limit is reflective of recent studies reporting that lowering dietary cholesterol may have relatively little effect on serum LDL-cholesterol (LDL-C), especially in comparison to other more efficacious dietary strategies ${ }^{(4)}$. However, a recent meta-analysis of forty interventional and prospective cohort studies on this topic indicated that dietary cholesterol should not be completely disregarded as a CVD risk factor ${ }^{(5)}$. That analysis showed that dietary cholesterol was not associated with increased risk of incident CVD, yet it statistically significantly increased serum total cholesterol (TC), LDL-C and the ratio of LDL-C to HDL-cholesterol (HDL-C). Importantly, results across studies in the meta-analysis were heterogeneous, and experts have suggested that adopting healthy dietary patterns 
should be emphasized over simply adhering to dietary cholesterol limits ${ }^{(6)}$.

Therefore, eggs may be suitable for inclusion in a healthy dietary pattern, especially since they contain highquality protein and several of the nutrients of concern for underconsumption outlined in the 2015-2020 Dietary Guidelines for Americans, including $\mathrm{Ca}, \mathrm{Fe}, \mathrm{Mg}, \mathrm{K}$, and vitamins A, D and E. However, it is not well established how eggs contribute to overall nutrient adequacy among Americans and whether their consumption is related to CVD risk in US adults. An analysis of data from the National Health and Nutrition Examination Survey (NHANES III, 1988-1994) showed that egg consumers tended to have greater intakes of most key micronutrients compared with non-consumers and that egg consumption was associated with lower serum TC concentration ${ }^{(7)}$. However, that analysis did not examine the relationship between egg intake and other biomarkers of CVD risk. Additionally, other studies have reported that Americans' egg consumption patterns have changed significantly in the last decade, and that overall per capita egg consumption increased by $11 \%$ from 2001-2002 to 2011$2012^{(8)}$. Given the current public health significance of CVD in the USA, and in light of shifting dietary patterns and nutritional recommendations, it is necessary to examine how eggs fit into Americans' diets and how they may be related to CVD risk. Therefore, the overall goal of the present study was to assess the nutritional significance of eggs in the American diet and to estimate the association between whole egg consumption and CVD risk factors. The central hypothesis of the study was that increased whole egg consumption is positively associated with nutrient adequacy of micronutrients such as folate, vitamin $\mathrm{B}_{12}$, vitamin $\mathrm{E}$, lutein plus zeaxanthin, Se and choline, and that an inverse association will be observed between egg intake and CVD risk related to increased concentrations of these nutrients as well as improved CVD risk biomarkers.

\section{Methods}

\section{Participants}

The present study utilized data from US adults aged 19 years or older from NHANES 2003-2012. NHANES uses a stratified, multistage probability sampling design with weighting to allow for nationally representative estimates to be generated for the civilian noninstitutionalized US population. Response rates in NHANES generally vary from 70 to $80 \%$, and sampling weights are created to account for differential probabilities of selection and non-response ${ }^{(9,10)}$. Exclusion criteria for the current analysis were women who were pregnant or lactating, those whose dietary recalls were coded as unreliable or incomplete, women taking oestrogen replacement therapy, and those whose recalls were coded as 'much more than usual' or 'much less than usual' so as to obtain the most accurate assessment of usual intake.

\section{Dietary intake data}

Nutrient intakes were estimated from $24 \mathrm{~h}$ dietary recall interviews conducted in NHANES 2003-2012. Dietary recalls were conducted by trained interviewers using the US Department of Agriculture's Automated Multiple-Pass Method. The first dietary recalls were conducted in person at mobile examination centres and the second recalls were conducted by telephone approximately 3-10 d after the first dietary recall. The US Department of Agriculture's National Nutrient Database for Standard Reference (SR) is the major source of food composition data in the USA. The US Department of Agriculture's Food and Nutrient Database for Dietary Studies (FNDDS) is the underlying database used to code dietary intake and to calculate nutrients for NHANES dietary data. Using the nutrient intake data generated in NHANES from these databases, individuals' dietary intakes were classified as either meeting or failing to meet the Estimated Average Requirement, the amount of a nutrient that is estimated to meet the requirement of half of the healthy individuals of a specific age, sex and life stage ${ }^{(11)}$. There are insufficient data to establish an Estimated Average Requirement for choline and vitamin $\mathrm{K}$, so participants were classified as meeting or failing to meet the Adequate Intake for these nutrients.

\section{Estimation of egg intake}

The FNDDS is based on nutrient values in the SR, and the associations between FNDDS foods and items from the SR are documented in NHANES data files. Searching these files allows for the determination of which SR items compose the foods and food mixtures included in FNDDS. To determine participants' whole egg consumption using dietary data from NHANES, the following procedure was applied. First, to find all food codes containing eggs, SR descriptions were searched for 'egg'. SR items that were composed entirely of egg, such as 'egg, whole, cooked, hard-boiled', were assumed to contain $100 \%$ egg. SR descriptions that included the word 'egg' and that contained a mixture of foods were examined further to determine the percentage of egg in the item. The Nutrition Data System for Research (NDSR) software was utilized for this process in addition to searches on popular recipe websites to determine typical egg content for these mixed items. For example, the SR code for the item 'shrimp egg foo yung' was assumed to contain $21.05 \%$ egg by weight based on the standard recipe used in NDSR for the item 'egg foo yung with sauce, with shrimp'. Similar procedures were performed for each distinct SR code containing 'egg' in its name. Foods containing only egg whites, egg yolks or egg substitutes were not included as egg sources in the 
analysis; only whole egg sources were considered in the definition of egg consumption for the present study. Next, FNDDS food files were searched for foods containing the SR codes designated as containing egg. Using the percentage of egg in each identified SR code and the percentage of the SR code present in the food, the percentage of egg by weight in each food was calculated. Finally, individuals' egg consumption was calculated by summing the egg weight contributed by each food recorded in the dietary recall.

\section{CVD risk factors and biochemical analyses}

Waist circumference (WC), height, weight and blood pressure were measured in mobile examination centres. Using height and weight values, BMI was calculated as $\mathrm{kg} / \mathrm{m}^{2}$. Blood nutrient concentrations as well as TC, TAG, HDL-C and C-reactive protein were measured following the methods described in the NHANES laboratory procedures $^{(12)}$. LDL-C was calculated using the Friedewald formula: LDL-C $=$ TC - HDL-C $-\mathrm{TAG} / 5^{(2)}$. Ratios of TC to HDL-C and TAG to HDL-C were also calculated.

\section{Statistical analysis}

Statistical analyses were conducted with the statistical software package SAS version 9.4 and the Survey Data Analysis for multistage sample designs professional software package (SUDAAN; Research Triangle Institute, Research Triangle Park, NC, USA), using SAS survey procedures including the appropriate weight, strata, domain and cluster variables to account for the complex survey design used in NHANES. Egg consumption was categorized into tertiles according to the distribution of participants. The $\chi^{2}$ test was used to assess the distribution of categorical variables. ANOVA was used to compare means for interval-scale variables and to test differences in egg consumption by sociodemographic and lifestyle characteristics. Arithmetic means of micronutrient intakes of sociodemographic subgroups were calculated, and standard errors were calculated by the linearization (Taylor series) variance estimation method for population parameters in SUDAAN. ANOVA and $t$ tests were used to compare means for interval-scale variables and to test differences between egg consumption groups. Mean blood nutrient concentrations and CVD risk factors by level of egg consumption were also calculated after log transformation. Multivariate linear regression analyses were performed to determine correlations between egg consumption and cardiovascular risk markers while controlling for other potential confounders including dietary factors that could be correlated with egg intake such as saturated fat and total energy intakes. $P$ values reported were two-tailed and statistical significance was defined as $P<0 \cdot 05$.

\section{Results}

Approximately $73 \%$ of adults were classified as whole egg consumers, with mean intake of $43 \cdot 1$ (sE 1.0) g/d among all adults and 59.3 (sE 1.3) g/d among egg consumers. Distribution of egg intake was skewed to the right, with a median egg intake of $27.6 \mathrm{~g} / \mathrm{d}$ among egg consumers. Differences in egg consumption patterns were noted among adults of different socio-economic and demographic groups (Table 1). Men were more likely than women to be high consumers of eggs, and those in older age groups were more likely to be egg consumers than those in younger age groups. Differences in egg consumption patterns also existed among ethnicities, with African Americans consuming eggs more frequently than any other group. Dietary supplement users were also more likely to be egg consumers than those not taking dietary supplements. Adults with CHD or diabetes were more likely to consume eggs than those without these diseases, and those who were overweight or obese were more likely to consume eggs than those with a BMI under $25 \mathrm{~kg} / \mathrm{m}^{2}$. Higher incomes and alcohol intake were positively associated with egg intake, while cigarette smoking and physical activity appeared to be negatively associated with egg consumption.

Higher consumption of eggs was associated with greater intakes of most essential vitamins and minerals examined after adjusting for gender, ethnicity, age, alcohol consumption, smoking status, dietary supplement use, total energy intake, income and physical activity level (Table 2). With adjustment for the same confounders, egg consumption was also associated with a lower prevalence of falling below the Estimated Average Requirement or Adequate Intake (Table 3). Egg consumption appeared to have the strongest relationship with the likelihood of meeting nutrient recommendations for choline, vitamin A and vitamin $\mathrm{B}_{12}$. For these nutrients, the prevalence of meeting the intake recommendation was $26.5,13.3$ and $10 \cdot 7$ percentage points greater among high consumers of eggs compared with non-consumers, respectively.

Egg consumption was not significantly associated with blood nutrient concentrations of most nutrients examined, except for positive trends with serum folate, erythrocyte folate, and lutein plus zeaxanthin (Table 4). After adjusting for gender, race, alcohol consumption status, smoking status, dietary supplement use, age, total energy intake, BMI, income, physical activity, diabetes, CHD and arthritis, there were no significant trends across tertiles of egg consumption for any of the CVD risk factors examined except apo B, which was highest among the middle tertile of egg consumers (Table 4).

In multivariable linear regression models, egg intake showed no significant association with systolic or diastolic blood pressure, HDL-C, LDL-C, TC or C-reactive protein after adjusting for several potential confounders (Table 5). Greater egg consumption was associated with statistically significant decreases in TAG, and modest but statistically 
Table 1 Sociodemographic, lifestyle and health-related characteristics by level of egg consumption among US adults aged $\geq 19$ years, National Health and Nutrition Examination Survey (NHANES) 2003-2012 ( $n$ 21845)

\begin{tabular}{|c|c|c|c|c|c|c|c|c|c|c|}
\hline \multirow[b]{3}{*}{ Characteristic } & \multirow[b]{3}{*}{ Total $n$} & \multicolumn{8}{|c|}{ Level of egg consumption } & \multirow[b]{3}{*}{$P$ value ${ }^{*}$} \\
\hline & & \multicolumn{2}{|c|}{ Non-consumers } & \multicolumn{2}{|c|}{ Tertile 1} & \multicolumn{2}{|c|}{ Tertile 2} & \multicolumn{2}{|c|}{ Tertile 3} & \\
\hline & & $n$ & Weighted \% & $n$ & Weighted \% & $n$ & Weighted \% & $n$ & Weighted \% & \\
\hline Total & 21845 & & 5871 & & 5320 & & 5334 & & 5320 & \\
\hline Gender & & & & & & & & & & $<0.0001$ \\
\hline Men & 11329 & 3003 & $27 \cdot 1$ & 2515 & 22.9 & 2754 & $24 \cdot 4$ & 3057 & $25 \cdot 6$ & \\
\hline Women & 10516 & 2868 & $27 \cdot 7$ & 28 & $28 \cdot 3$ & 2882 & $26 \cdot 5$ & 1901 & $17 \cdot 5$ & \\
\hline Age (years) & & & & & & & & & & $<0.0001$ \\
\hline 19-39 & 7668 & 2302 & $30 \cdot 7$ & 1821 & $24 \cdot 6$ & 1899 & $24 \cdot 4$ & 1646 & $20 \cdot 4$ & \\
\hline $40-59$ & 6725 & 1761 & $26 \cdot 7$ & 1586 & $24 \cdot 7$ & 1767 & $26 \cdot 5$ & 1611 & $22 \cdot 2$ & \\
\hline$\geq 60$ & 7452 & 1808 & $23 \cdot 6$ & 1973 & $28 \cdot 2$ & 1970 & $25 \cdot 6$ & 1701 & $22 \cdot 7$ & \\
\hline Ethnicity & & & & & & & & & & $<0.0001$ \\
\hline Non-Hispanic White & 10633 & 2943 & $28 \cdot 0$ & 2849 & $26 \cdot 5$ & 2696 & $25 \cdot 1$ & 2145 & $20 \cdot 4$ & \\
\hline Non-Hispanic Black & 4459 & 998 & $22 \cdot 0$ & 1151 & $26 \cdot 4$ & 1206 & $27 \cdot 5$ & 1104 & $24 \cdot 1$ & \\
\hline Mexican-American \& Hispanic & 5321 & 1514 & $28 \cdot 3$ & 1057 & $19 \cdot 7$ & 1390 & $25 \cdot 0$ & 1360 & $27 \cdot 0$ & \\
\hline Others & 1432 & 416 & $27 \cdot 2$ & 323 & $24 \cdot 1$ & 344 & $27 \cdot 6$ & 349 & $21 \cdot 0$ & \\
\hline Income† & & & & & & & & & & 0.0030 \\
\hline $\mathrm{PIR}<1.30$ & 7874 & 2308 & $30 \cdot 0$ & 1811 & 23.9 & 1911 & $24 \cdot 0$ & 1844 & $22 \cdot 1$ & \\
\hline $1.30 \geq P I R \leq 3.50$ & 7715 & 2010 & $27 \cdot 1$ & 1922 & $25 \cdot 8$ & 2033 & $25 \cdot 4$ & 1750 & $21 \cdot 7$ & \\
\hline $\mathrm{PIR}>3.50$ & 6256 & 1553 & $26 \cdot 0$ & 1647 & $26 \cdot 3$ & 1692 & $26 \cdot 5$ & 1364 & $21 \cdot 3$ & \\
\hline BMI $\left(\mathrm{kg} / \mathrm{m}^{2}\right)$ & & & & & & & & & & 0.0003 \\
\hline $\mathrm{BMI}<18.5$ & 672 & 202 & 33.9 & 175 & $27 \cdot 0$ & 163 & $23 \cdot 4$ & 132 & $15 \cdot 7$ & \\
\hline $18.5 \leq \mathrm{BMI}<25.0$ & 6299 & 1731 & $28 \cdot 2$ & 1595 & $26 \cdot 6$ & 1622 & $25 \cdot 7$ & 1351 & $19 \cdot 6$ & \\
\hline $25 \leq \overline{B M I}<30.0$ & 7288 & 1951 & $27 \cdot 4$ & 1825 & 25.9 & 1840 & 24.9 & 1672 & $21 \cdot 8$ & \\
\hline $\mathrm{BMI} \geq 30 \cdot 0$ & 7586 & 1987 & $26 \cdot 1$ & 1785 & $24 \cdot 1$ & 2011 & $26 \cdot 1$ & 1803 & $23 \cdot 8$ & \\
\hline Alcohol consumption & & & & & & & & & & $<0.0001$ \\
\hline$\geq 12$ drinks per year & 14224 & 3729 & $27 \cdot 0$ & 3416 & $25 \cdot 0$ & 3619 & $25 \cdot 1$ & 3460 & 22.9 & \\
\hline$<12$ drinks per year & 5520 & 1513 & $27 \cdot 7$ & 1453 & $27 \cdot 4$ & 1499 & $27 \cdot 0$ & 1055 & $18 \cdot 0$ & \\
\hline Smoking statusł & & & & & & & & & & 0.0077 \\
\hline Current smoker & 4559 & 1296 & $28 \cdot 8$ & 1057 & $25 \cdot 1$ & 1072 & $23 \cdot 4$ & 1134 & $22 \cdot 7$ & \\
\hline Current non-smoker & 17285 & 4574 & $27 \cdot 0$ & 4323 & $25 \cdot 7$ & 4564 & $26 \cdot 0$ & 3824 & $21 \cdot 3$ & \\
\hline Dietary supplement use§ & & & & & & & & & & 0.0053 \\
\hline Yes & 10491 & 2647 & $26 \cdot 2$ & 2684 & $26 \cdot 1$ & 2789 & $26 \cdot 3$ & 2371 & $21 \cdot 5$ & \\
\hline No & 11341 & 3221 & $28 \cdot 7$ & 2694 & $25 \cdot 0$ & 2843 & $24 \cdot 6$ & 2583 & $21 \cdot 8$ & \\
\hline Physical activity level\| & & & & & & & & & & 0.0004 \\
\hline 1 & 5720 & 1489 & $25 \cdot 5$ & 1398 & $25 \cdot 8$ & 1448 & $24 \cdot 3$ & 1385 & 24.5 & \\
\hline 2 & 2773 & 763 & $27 \cdot 6$ & 695 & $26 \cdot 3$ & 684 & $24 \cdot 6$ & 631 & $21 \cdot 5$ & \\
\hline 3 & 2891 & 833 & $30 \cdot 7$ & 695 & $24 \cdot 4$ & 684 & $23 \cdot 1$ & 679 & $21 \cdot 8$ & \\
\hline 4 & 2843 & 822 & 28.5 & 648 & $24 \cdot 6$ & 630 & $21 \cdot 4$ & 743 & $25 \cdot 5$ & \\
\hline $\mathrm{CHD}$ & & & & & & & & & & 0.0103 \\
\hline Yes & 950 & 213 & $23 \cdot 1$ & 267 & $30 \cdot 1$ & 239 & $24 \cdot 7$ & 231 & $22 \cdot 2$ & \\
\hline No & 20018 & 5357 & $27 \cdot 4$ & 4895 & $25 \cdot 4$ & 5206 & $25 \cdot 6$ & 4560 & $21 \cdot 6$ & \\
\hline Diabetes & & & & & & & & & & 0.0009 \\
\hline Yes & 2549 & 612 & $24 \cdot 4$ & 579 & $22 \cdot 7$ & 673 & $27 \cdot 0$ & 685 & $26 \cdot 0$ & \\
\hline No & 18892 & 5159 & $27 \cdot 7$ & 4705 & $25 \cdot 8$ & 4855 & $25 \cdot 4$ & 4173 & $21 \cdot 2$ & \\
\hline Arthritis & & & & & & & & & & 0.0003 \\
\hline Yes & 5808 & 1446 & 24.9 & 1560 & $27 \cdot 7$ & 1519 & $24 \cdot 7$ & 1283 & $22 \cdot 7$ & \\
\hline No & 15209 & 4137 & $28 \cdot 0$ & 3616 & 24.5 & 3940 & $24 \cdot 2$ & 3516 & $23 \cdot 3$ & \\
\hline
\end{tabular}

PIR, poverty income ratio.

${ }^{\star} P$ values determined from $x^{2}$ test between subgroups.

†Income assessed as ratio of the median family income to the poverty index. A PIR $<1.30$ is required to be eligible for food assistance programmes and a PIR $<1.85$ is required to be eligible for the Special Supplemental Nutrition Program for Women, Infants, and Children.

$\ddagger$ Current smokers defined as those currently smoking cigarettes on at least 'some days'.

§Dietary supplement use defined as those taking any dietary supplements including vitamins, minerals or other dietary supplements at the time of interview.

$\|$ Physical activity levels, expressed using the MET (metabolic equivalent of task) score, were calculated by combining the intensity level of the leisure-time activities reported, mean duration and frequency.

significant decreases in TAG:HDL-C and TC:HDL-C. Egg consumption was also associated with statistically significant increases in both WC and BMI.

\section{Discussion}

The present study demonstrates that whole egg consumption is associated with greater likelihood of meeting nutrient recommendations for many key micronutrients. As has been documented previously, the present study shows that a large proportion of Americans fail to meet recommended intakes for many nutrients ${ }^{(13,14)}$, but the results also indicate that the likelihood of meeting the Estimated Average Requirement or Adequate Intake for many nutrients is significantly higher than among whole egg consumers than among non-consumers, especially for choline, vitamin $\mathrm{A}$, vitamin $\mathrm{B}_{12}, \mathrm{Zn}$ and riboflavin. This is 
Table 2 Mean daily nutrient intakes by level of egg consumption among US adults aged $\geq 19$ years, National Health and Nutrition Examination Survey (NHANES) 2003-2012 ( $n$ 21845)

\begin{tabular}{|c|c|c|c|c|c|c|}
\hline \multirow[b]{2}{*}{ Nutrient } & \multicolumn{6}{|c|}{ Level of egg consumption } \\
\hline & $\begin{array}{c}\text { All } \\
\text { (n 21845) }\end{array}$ & $\begin{array}{l}\text { Non-consumers } \\
(n 5871)\end{array}$ & $\begin{array}{l}\text { Tertile } 1 \\
(n 5320)\end{array}$ & $\begin{array}{l}\text { Tertile } 2 \\
\text { (n 5334) }\end{array}$ & $\begin{array}{l}\text { Tertile } 3 \\
(n 5320)\end{array}$ & $P$ for trend ${ }^{*}$ \\
\hline Egg intake $(g / d)$, mean & $\begin{array}{c}43 \cdot 1 \\
0.0-1761.4\end{array}$ & $\begin{array}{r}0.0 \\
0.0-0.0\end{array}$ & $\begin{array}{c}4.5 \\
0.1-10.7\end{array}$ & $\begin{array}{c}28.0 \\
10.7-55.6\end{array}$ & $\begin{array}{c}152 \cdot 0 \\
55 \cdot 6-1761 \cdot 4\end{array}$ & $<0.0001$ \\
\hline \multicolumn{7}{|l|}{ Macronutrients and lipids } \\
\hline Protein $(\mathrm{g} / \mathrm{d})$ & 84.9 & $78 \cdot 8$ & 78.6 & 87.8 & $95 \cdot 8$ & $<0.0001$ \\
\hline Carbohydrates $(\mathrm{g} / \mathrm{d})$ & $262 \cdot 9$ & $251 \cdot 3$ & $258 \cdot 3$ & 273.4 & 270.9 & $<0.0001$ \\
\hline Total fat $(\mathrm{g} / \mathrm{d})$ & 81.7 & 71.8 & 75.7 & 85.4 & 95.9 & $<0.0001$ \\
\hline Saturated fat $(g / d)$ & $26 \cdot 82$ & 24.0 & 24.5 & $27 \cdot 9$ & 31.5 & $<0.0001$ \\
\hline Monounsaturated fat $(\mathrm{g} / \mathrm{d})$ & 29.81 & $26 \cdot 1$ & $27 \cdot 6$ & $31 \cdot 1$ & $35 \cdot 3$ & $<0.0001$ \\
\hline Polyunsaturated fat $(\mathrm{g} / \mathrm{d})$ & 17.99 & $15 \cdot 6$ & $17 \cdot 2$ & 18.9 & $20 \cdot 8$ & $<0.0001$ \\
\hline Cholesterol (mg/d) & $290 \cdot 3$ & 178.8 & $199 \cdot 6$ & $300 \cdot 5$ & 510.5 & $<0.0001$ \\
\hline \multicolumn{7}{|l|}{ Vitamins } \\
\hline Vitamin $A(\mu \mathrm{g} / \mathrm{d})$ & $660 \cdot 7$ & 614.7 & 632.5 & 651.9 & $755 \cdot 1$ & $<0.0001$ \\
\hline Thiamin $(\mathrm{mg} / \mathrm{d})$ & 1.7 & 1.7 & 1.6 & 1.8 & 1.8 & $<0.0001$ \\
\hline Riboflavin (mg/d) & $2 \cdot 3$ & $2 \cdot 1$ & $2 \cdot 1$ & $2 \cdot 3$ & $2 \cdot 6$ & $<0.0001$ \\
\hline Niacin $(\mathrm{mg} / \mathrm{d})$ & $26 \cdot 1$ & $25 \cdot 7$ & 25.4 & $26 \cdot 7$ & $26 \cdot 9$ & $<0.0001$ \\
\hline Folate $(\mu \mathrm{g}$ DFE $/ \mathrm{d})$ & 568.4 & $562 \cdot 1$ & $561 \cdot 1$ & $580 \cdot 8$ & $570 \cdot 9$ & $<0.0001$ \\
\hline Vitamin $B_{6}(\mathrm{mg} / \mathrm{d})$ & $2 \cdot 1$ & $2 \cdot 1$ & $2 \cdot 1$ & $2 \cdot 1$ & $2 \cdot 2$ & $<0.0001$ \\
\hline Vitamin $\mathrm{B}_{12}(\mathrm{mg} / \mathrm{d})$ & 5.5 & $5 \cdot 3$ & $5 \cdot 3$ & $5 \cdot 4$ & $6 \cdot 2$ & 0.0108 \\
\hline Vitamin D ( $\mu \mathrm{g} / \mathrm{d})$ & 4.9 & 4.4 & 4.5 & 4.8 & 5.9 & $<0.0001$ \\
\hline Vitamin E (mg a-TE/d) & $109 \cdot 6$ & $105 \cdot 2$ & $107 \cdot 1$ & $113 \cdot 0$ & $113 \cdot 8$ & 0.0045 \\
\hline Vitamin $\mathrm{K}(\mu \mathrm{g} / \mathrm{d})$ & 109.6 & 105.2 & $107 \cdot 1$ & $113 \cdot 0$ & $113 \cdot 8$ & 0.80 \\
\hline \multicolumn{7}{|l|}{ Minerals } \\
\hline $\mathrm{Mg}(\mathrm{mg} / \mathrm{d})$ & 303.2 & $295 \cdot 1$ & $291 \cdot 7$ & $306 \cdot 7$ & 321.6 & $<0.0001$ \\
\hline$P(\mathrm{mg} / \mathrm{d})$ & $1394 \cdot 1$ & 1311.0 & 1294.3 & $1426 \cdot 0$ & $1567 \cdot 8$ & $<0.0001$ \\
\hline $\mathrm{Fe}(\mathrm{mg} / \mathrm{d})$ & 970.0 & $947 \cdot 8$ & $916 \cdot 2$ & 981.6 & $1042 \cdot 9$ & $<0.0001$ \\
\hline $\mathrm{Ca}(\mathrm{mg} / \mathrm{d})$ & $970 \cdot 0$ & $947 \cdot 8$ & $916 \cdot 2$ & 981.6 & $1042 \cdot 9$ & $<0.0001$ \\
\hline $\mathrm{Zn}(\mathrm{mg} / \mathrm{d})$ & $12 \cdot 3$ & 11.8 & $11 \cdot 8$ & 12.5 & $13 \cdot 3$ & 0.0420 \\
\hline Se $(\mu \mathrm{g} / \mathrm{d})$ & 114.8 & $101 \cdot 1$ & 103.7 & 121.5 & $136 \cdot 1$ & $<0.0001$ \\
\hline \multicolumn{7}{|l|}{ Carotenoids } \\
\hline Lycopene $(\mu \mathrm{g} / \mathrm{d})$ & 5849.9 & $5346 \cdot 8$ & $5645 \cdot 2$ & $6502 \cdot 3$ & $5985 \cdot 2$ & 0.0036 \\
\hline Lutein + zeaxanthin $(\mu \mathrm{g} / \mathrm{d})$ & 1573.6 & 1459.4 & 1508.4 & $1579 \cdot 3$ & 1773.9 & 0.0019 \\
\hline$a-C a r o t e n e(\mu g / d)$ & 453.5 & 446.8 & 453.7 & $432 \cdot 2$ & $405 \cdot 9$ & 0.25 \\
\hline$\beta$-Carotene $(\mu \mathrm{g} / \mathrm{d})$ & $2260 \cdot 2$ & $2261 \cdot 2$ & $2303 \cdot 3$ & $2250 \cdot \overline{7}$ & $2222 \cdot 2$ & 0.43 \\
\hline$\beta$-Cryptoxanthin $(\mu \mathrm{g} / \mathrm{d})$ & $106 \cdot 4$ & $97 \cdot 0$ & $103 \cdot 0$ & $112 \cdot 7$ & 114.6 & 0.54 \\
\hline \multicolumn{7}{|l|}{ Other components } \\
\hline Choline (mg/d) & 336.5 & $270 \cdot 7$ & 278.7 & 341.6 & $470 \cdot 8$ & $<0.0001$ \\
\hline
\end{tabular}

DFE, dietary folate equivalents; $a-T E$, a-tocopherol equivalents.

*Adjusted for gender, ethnicity, age, alcohol consumption status, smoking status, dietary supplement use, total energy intake, income and physical activity level.

in agreement with an older analysis that examined NHANES III data collected during 1988-1994, showing that eggs were an important source of many micronutrients in the American $\operatorname{diet}^{(7)}$. Similarly, other work examining NHANES data has demonstrated that highquality protein sources such as eggs are vital for achieving protein recommendations as well as micronutrient recommendations ${ }^{(15)}$.

Other studies have indirectly examined the nutritional contribution of eggs to American diets by comparing the diets of individuals with different breakfast choices. Two studies examining adults' breakfast patterns using NHANES data suggested that breakfast patterns consisting of ready-to-eat cereals, grains, low-fat dairy and fruit were associated with better overall nutritional quality than breakfast patterns that included eggs ${ }^{(16,17)}$. Conversely, the present study, which accounts for egg consumption at all eating occasions, suggests that egg consumers may be more successful in achieving the recommendations for key micronutrients than those who avoid eggs. This apparent discrepancy is indicative of the wide variability in egg consumption patterns and may suggest that consumption of eggs at different eating occasions may be associated with varied accompanying dietary choices.

The present study also differs from several previous reports due to its inclusion of a wider variety of egg sources. In FNDDS, each food is assigned to one of nine major food groups: (i) milk products, (ii) meat/poultry/ fish, (iii) eggs, (iv) legumes/nuts/seeds, (v) grain products, (vi) fruits, (vii) vegetables, (viii) fats/oils and (ix) sweets/ beverages. Whereas many previous studies examining egg intake considered only foods categorized in the egg food group $^{(7,8)}$, the present study includes many additional sources of eggs that may fall into other food groups such as egg-containing sandwiches, soups, pies or other mixed dishes. Therefore, the more exhaustive methods used in the present study may provide a more accurate assessment of Americans' egg consumption.

While these results show that whole eggs contribute meaningfully to the micronutrient intakes of many 
Table 3 Percentage of US adults aged $\geq 19$ years falling below dietary micronutrient recommendations by level of egg consumption, National Health and Nutrition Examination Survey (NHANES) 2003-2012 (n 21845)*,$\dagger$

\begin{tabular}{lcccccc}
\hline \multicolumn{6}{c}{ Level of egg consumption } \\
\cline { 2 - 7 } Nutrient & $\begin{array}{c}\text { All } \\
(n \text { 21 845) }\end{array}$ & $\begin{array}{c}\text { Non-consumers } \\
(n \text { 5871) }\end{array}$ & $\begin{array}{c}\text { Tertile 1 } \\
(n \text { 5320) }\end{array}$ & $\begin{array}{c}\text { Tertile 2 } \\
(n \text { 5334) }\end{array}$ & $\begin{array}{c}\text { Tertile 3 } \\
(n \text { 5320 })\end{array}$ & $P$ for trend \\
\hline Vitamin D & 93.4 & 93.6 & 94.5 & 94.0 & 91.4 & 0.07 \\
Choline & 88.6 & 95.8 & 96.0 & 91.0 & 69.3 & $<0.0001$ \\
Vitamin E & 84.9 & 87.0 & 86.2 & 84.7 & 81.1 & 0.27 \\
Vitamin K & 69.6 & 74.7 & 69.4 & 65.2 & 68.4 & 0.0006 \\
Mg & 57.5 & 59.6 & 59.6 & 55.7 & 53.9 & $<0.0001$ \\
Vitamin A & 51.9 & 57.3 & 54.2 & 50.8 & 44.0 & $<0.0001$ \\
Ca & 49.4 & 50.9 & 54.0 & 48.7 & 43.4 & $<0.0001$ \\
Zn & 25.7 & 29.4 & 28.5 & 23.9 & 20.3 & $<0.0001$ \\
Vitamin $B_{6}$ & 20.3 & 22.4 & 22.2 & 20.1 & 15.8 & 0.07 \\
Folate & 21.7 & 26.1 & 22.9 & 18.5 & 18.4 & 0.0088 \\
Thiamin & 15.1 & 19.5 & 16.2 & 12.4 & 11.6 & 0.73 \\
Vitamin $B_{12}$ & 14.7 & 18.6 & 18.3 & 13.3 & 7.9 & $<0.0001$ \\
Riboflavin & 7.4 & 11.6 & 9.2 & 5.3 & 2.8 & $<0.0001$ \\
Niacin & 6.8 & 8.5 & 7.0 & 5.8 & 5.8 & 0.0002 \\
Fe & 6.7 & 10.4 & 7.1 & 5.2 & 3.7 & $<0.0001$ \\
Se & 4.8 & 8.5 & 5.9 & 2.9 & 1.2 & $<0.0001$ \\
P & 4.2 & 6.4 & 5.5 & 2.8 & 1.2 & $<0.0001$ \\
\hline
\end{tabular}

*Based on the Estimated Average Requirement, or Adequate Intake when an Estimated Average Requirement has not been established (choline and vitamin K).

†Adjusted for gender, ethnicity, age, alcohol consumption status, smoking status, dietary supplement use, total energy intake, income and physical activity level.

Americans, the results show that egg consumption is not related to blood nutrient concentrations for many of the nutrients examined. This is not unexpected, as blood concentrations of many of the nutrients assessed, such as $\mathrm{Ca}$ and $\mathrm{P}$, are tightly controlled through homeostatic mechanisms ${ }^{(18,19)}$. One notable exception is the significant, positive association between egg intake and plasma lutein plus zeaxanthin. Lutein and zeaxanthin are believed to prevent damage that can lead to age-related macular degeneration ${ }^{(20)}$, and may also exert neuroprotective effects through reduction of oxidative stress and inflammation $^{(21)}$. In addition to higher total intakes of lutein plus zeaxanthin in higher egg consumers, the positive trend in plasma level of these carotenoids with egg consumption may also be related to the high bioavailability of lutein and zeaxanthin from eggs compared with other top sources such as kale, spinach, peas and brussels sprouts ${ }^{(20)}$. Egg consumption was also positively associated with both serum folate and erythrocyte folate, two biomarkers that are known to be influenced by diet as well as physiological factors including age and disease state $^{(22)}$. Therefore, because folate consumption tended to be greater in adults with greater egg intake, it is unsurprising that erythrocyte folate, which is particularly useful as an indicator of long-term folate status, was strongly associated with whole egg consumption in the present study.

The association of whole egg intake with biomarkers of CVD risk was mixed in the present study, which suggests that whole egg consumption is not associated with blood pressure or blood concentrations of TC, HDL-C, LDL-C, insulin or fasting glucose. Egg intake was inversely associated with serum TAG in multivariable regression models, but egg consumption was also associated with higher BMI and WC. Overall, these findings add to a growing body of complex and inconsistent data on this topic. A recent meta-analysis examining forty studies on this topic published from 1979 to 2013 pointed out that the available literature is highly heterogeneous, and that the data are insufficient for drawing well-supported conclusions regarding the effects of egg intake or dietary cholesterol on CVD risk ${ }^{(5)}$. Another systematic review of the most recent literature (2005-2015) reported that egg consumption tends to be related to non-significant increases in CVD risk factors in interventional trials, and that among observational studies, there is no consensus of any association between egg consumption and CVD risk ${ }^{(23)}$.

Other meta-analyses, however, have indicated that egg consumption may either protect against or have no relationship with CVD risk. A 2016 meta-analysis showed that 'high' consumption of eggs (usually defined as one egg daily) was associated with a $12 \%$ reduction in stroke risk compared with low egg intake (usually defined as less than two eggs weekly) based on data from seven prospective cohort studies ${ }^{(24)}$. That analysis also investigated the relationship between egg intake and CHD risk, and found no clear association among seven prospective cohorts. A 2013 meta-analysis of prospective cohort studies found that consumption of up to one egg per day was not associated with risk of either stroke or $\mathrm{CHD}^{(25)}$. Furthermore, a 2018 meta-analysis showed that higher egg consumption $(7+$ eggs/week $)$ had no association with 
Table 4 Mean blood nutrient, lipid and glucose levels by level of egg consumption among US adults aged $\geq 19$ years, National Health and Nutrition Examination Survey (NHANES) 2003-2012 (n 21845$)^{\star}$,

\begin{tabular}{|c|c|c|c|c|c|c|c|c|c|c|}
\hline & \multirow[b]{3}{*}{ Total $n$} & \multicolumn{8}{|c|}{ Level of egg consumption } & \multirow[b]{3}{*}{$P$ for trend } \\
\hline & & \multicolumn{2}{|c|}{ Non-consumers } & \multicolumn{2}{|c|}{ Tertile 1} & \multicolumn{2}{|c|}{ Tertile 2} & \multicolumn{2}{|c|}{ Tertile 3} & \\
\hline & & Mean & SE & Mean & SE & Mean & SE & Mean & SE & \\
\hline \multicolumn{11}{|l|}{ Nutrients } \\
\hline $\mathrm{Fe}(\mu \mathrm{g} / \mathrm{dl})$ & 20594 & $79 \cdot 8$ & 1.01 & $79 \cdot 8$ & 1.01 & $80 \cdot 6$ & 1.01 & $80 \cdot 6$ & 1.01 & $0 \cdot 14$ \\
\hline $\mathrm{Zn}(\mu \mathrm{mol} / \mathrm{l})$ & 1344 & $12 \cdot 4$ & 1.01 & 12.5 & 1.02 & $12 \cdot 7$ & 1.02 & $12 \cdot 7$ & 1.01 & 0.82 \\
\hline$P(m g / d l)$ & 20605 & 3.7 & 1.00 & 3.7 & 1.00 & 3.7 & 1.00 & $3 \cdot 7$ & 1.00 & 0.20 \\
\hline $\mathrm{K}(\mathrm{mmol} / \mathrm{l})$ & 20606 & 4.0 & 1.00 & 4.0 & 1.00 & 4.0 & 1.00 & 4.0 & 1.00 & $0 \cdot 16$ \\
\hline $\mathrm{Ca}(\mathrm{mmol} / \mathrm{l})$ & 20608 & 9.5 & 1.00 & 9.5 & 1.00 & 9.5 & 1.00 & 9.5 & 1.00 & 0.07 \\
\hline Se $(\mu g / l)$ & 3657 & $131 \cdot 6$ & 1.01 & $133 \cdot 0$ & 1.01 & $134 \cdot 3$ & 1.01 & 133.0 & 1.01 & 0.08 \\
\hline Vitamin A $(\mu \mathrm{g} / \mathrm{dl})$ & 7197 & $58 \cdot 6$ & 1.01 & 57.4 & 1.01 & $59 \cdot 1$ & 1.01 & 58.6 & 1.01 & 0.09 \\
\hline Vitamin $\mathrm{B}_{6}(\mathrm{nmol} / \mathrm{l})$ & 16510 & $49 \cdot 9$ & 1.02 & $49 \cdot 4$ & 1.02 & 49.9 & 1.02 & $49 \cdot 4$ & 1.02 & 0.71 \\
\hline Vitamin $B_{12}(p m o l / l)$ & 11080 & $487 \cdot 8$ & 1.02 & $478 \cdot 2$ & 1.01 & $478 \cdot 2$ & 1.01 & 487.8 & 1.02 & 0.30 \\
\hline Serum folate $(\mathrm{nmol} / \mathrm{l})$ & 20661 & $14 \cdot 0$ & 1.01 & $15 \cdot 0$ & 1.02 & 14.6 & 1.01 & $15 \cdot 0$ & 1.01 & 0.0321 \\
\hline Erythrocyte folate (ng/ml) & 20803 & $387 \cdot 6$ & 1.01 & 387.6 & 1.02 & 379.9 & 1.01 & 391.5 & 1.01 & 0.0021 \\
\hline$a-C a r o t e n e(\mu \mathrm{g} / \mathrm{dl})$ & 7193 & $2 \cdot 7$ & 1.04 & $2 \cdot 7$ & 1.04 & $2 \cdot 8$ & 1.04 & $2 \cdot 6$ & 1.05 & 0.88 \\
\hline$\beta$-Carotene $(\mu \mathrm{mol} / \mathrm{l})$ & 3561 & 11.8 & 1.06 & $12 \cdot 9$ & 1.06 & $12 \cdot 7$ & 1.05 & 11.6 & 1.04 & 0.63 \\
\hline$\beta$-Cryptoxanthin ( $\mu \mathrm{g} / \mathrm{dl})$ & 7171 & $7 \cdot 2$ & 1.03 & $7 \cdot 0$ & 1.02 & $7 \cdot 2$ & 1.03 & $7 \cdot 2$ & 1.03 & $0 \cdot 18$ \\
\hline Lycopene ( $\mu \mathrm{g} / \mathrm{dl})$ & 7153 & 38.5 & 1.02 & $37 \cdot 0$ & 1.02 & $39 \cdot 3$ & 1.02 & $38 \cdot 1$ & 1.02 & 0.15 \\
\hline Lutein + zeaxanthin $(\mu \mathrm{g} / \mathrm{dl})$ & 7179 & 13.5 & 1.03 & $13 \cdot 7$ & 1.02 & 14.4 & 1.02 & $15 \cdot 2$ & 1.02 & $<0.0001$ \\
\hline $25(\mathrm{OH}) \mathrm{D}(\mathrm{nmol} / \mathrm{l})$ & 8848 & $62 \cdot 8$ & 1.01 & 63.4 & 1.02 & $62 \cdot 2$ & 1.02 & $62 \cdot 2$ & 1.02 & 0.67 \\
\hline Vitamin $E(\mu \mathrm{mol} / \mathrm{l})$ & 7197 & $1199 \cdot 9$ & 1.02 & $1199 \cdot 9$ & 1.01 & $1236 \cdot 5$ & 1.01 & $1236 \cdot 5$ & 1.02 & 0.41 \\
\hline \multicolumn{11}{|c|}{ Blood lipids and glucose markers } \\
\hline $\mathrm{TC}(\mathrm{mg} / \mathrm{dl})$ & 20684 & 192.5 & 1.00 & $192 \cdot 5$ & 1.00 & $192 \cdot 5$ & 1.00 & $192 \cdot 5$ & 1.00 & 0.50 \\
\hline TAG (mg/dl) & 10074 & 114.4 & 1.01 & $113 \cdot 3$ & 1.02 & $113 \cdot 3$ & 1.02 & 114.4 & 1.02 & 0.34 \\
\hline HDL-C (mg/dl) & 17013 & $50 \cdot 4$ & 1.01 & $50 \cdot 9$ & 1.01 & $50 \cdot 4$ & 1.01 & 49.9 & 1.01 & 0.36 \\
\hline LDL-C (mg/dl) & 9851 & $110 \cdot 0$ & 1.01 & $110 \cdot 0$ & 1.01 & $110 \cdot 0$ & 1.01 & $110 \cdot 0$ & 1.01 & 0.84 \\
\hline TC:HDL-C & 17013 & 3.8 & 1.01 & 3.8 & 1.01 & 3.8 & 1.01 & 3.9 & 1.01 & 0.53 \\
\hline TAG:HDL-C & 8334 & $2 \cdot 3$ & 1.01 & $2 \cdot 2$ & 1.01 & $2 \cdot 2$ & 1.02 & $2 \cdot 3$ & 1.02 & 0.37 \\
\hline LDL-C:HDL-C & 8158 & $2 \cdot 1$ & 1.01 & $2 \cdot 1$ & 1.01 & $2 \cdot 1$ & 1.01 & $2 \cdot 1$ & 1.01 & 0.35 \\
\hline Fasting glucose (mg/dl) & 10156 & 101.5 & 1.01 & $100 \cdot 5$ & 1.01 & 101.5 & 1.01 & $104 \cdot 6$ & 1.01 & $0 \cdot 16$ \\
\hline Insulin (uU/ml) & 9965 & $9 \cdot 3$ & 1.02 & $9 \cdot 2$ & 1.02 & $9 \cdot 3$ & 1.02 & $9 \cdot 8$ & 1.02 & 0.57 \\
\hline Apo B (mg/dl) & 8356 & $90 \cdot 0$ & 1.01 & $90 \cdot 0$ & 1.01 & $90 \cdot 9$ & 1.01 & $89 \cdot 1$ & 1.01 & 0.0021 \\
\hline
\end{tabular}

25(OH)D, 25-hydroxyergocaciferal (25-hydroxyvitamin $\mathrm{D}_{2}$ ) +25-hydroxycholecalciferol (25-hydroxyvitamin $\mathrm{D}_{3}$ ); TC, total cholesterol; HDL-C, HDL-cholesterol; LDL-C, LDL-cholesterol.

†Analyses adjusted for gender, race, alcohol consumption status, smoking status, dietary supplement use, age, total energy intake, BMI, income, physical activity, diabetes, CHD and arthritis. 
Table 5 Association between cardiovascular disease risk factors and egg consumption among adults aged $\geq 19$ years, National Health and Nutrition Examination Survey (NHANES) 2003-2012 (n 21845 )

\begin{tabular}{|c|c|c|c|c|c|c|}
\hline & \multicolumn{6}{|c|}{ Estimated difference in CVD risk factor with additional consumption of one egg } \\
\hline & \multicolumn{2}{|c|}{ Model $1 \dagger$} & \multirow[b]{2}{*}{$P$ value } & \multicolumn{2}{|c|}{ Model $2 \ddagger$} & \multirow[b]{2}{*}{$P$ value } \\
\hline & Difference & $95 \% \mathrm{Cl}$ & & Difference & $95 \% \mathrm{Cl}$ & \\
\hline \multicolumn{7}{|c|}{ Blood pressure $(\mathrm{mmHg})$} \\
\hline Systolic & -0.01 & $-0.14,0.13$ & 0.94 & 0.01 & $-0.14,0.16$ & 0.88 \\
\hline Diastolic & 0.05 & $-0.06,0.16$ & 0.41 & 0.08 & $-0.03,0.19$ & 0.16 \\
\hline WC (cm) & 0.32 & $0.14,0.51$ & 0.0009 & 0.25 & $0.07,0.44$ & 0.0069 \\
\hline BMI $\left(\mathrm{kg} / \mathrm{m}^{2}\right)$ & 0.14 & $0.05,0.22$ & 0.0017 & 0.11 & $0.03,0.19$ & 0.0080 \\
\hline HDL-C (mg/dl) & 0.07 & $-0.02,0.16$ & 0.14 & 0.08 & $-0.02,0.17$ & 0.12 \\
\hline LDL-C (mg/dl) & -0.24 & $-0.62,0.14$ & 0.22 & -0.18 & $-0.54,0.18$ & 0.33 \\
\hline $\mathrm{TC}(\mathrm{mg} / \mathrm{dl})$ & -0.32 & $-0.68,0.03$ & 0.07 & -0.29 & $-0.66,0.08$ & 0.12 \\
\hline TAG (mg/dl) & -1.67 & $-2.74,-0.60$ & 0.0025 & -1.75 & $-2.87,-0.63$ & 0.0025 \\
\hline TAG:HDL-C & -0.04 & $-0.07,-0.01$ & 0.0203 & -0.04 & $-0.08,-0.01$ & 0.0190 \\
\hline TC:HDL-C & -0.02 & $-0.02,-0.01$ & 0.0005 & -0.02 & $-0.03,-0.01$ & 0.0011 \\
\hline CRP (mg/l) & 0.00 & $-0.02,0.01$ & 0.63 & -0.01 & $-0.02,0.01$ & 0.35 \\
\hline
\end{tabular}

WC, waist circumference; HDL-C, HDL-cholesterol; LDL-C, LDL-cholesterol; TC, total cholesterol; CRP, C-reactive protein. *Based on additional consumption of one medium egg $(44 \mathrm{~g})$ per day. †Model 1: adjusted for age, gender, ethnicity, physical activity, income, smoking, alcohol consumption, BMI, energy intake and dietary supplement use (no adjustment for BMI when assessing BMI and WC).

¥Model 2: model 1 with additional adjustment for saturated fat intake, fibre intake, arthritis, CHD and diabetes.

CVD or all-cause mortality, and that it was associated with a slight but statistically significant reduction in stroke $\operatorname{risk}^{(26)}$.

Although much research indicates that eggs are either associated with modest protective effects in relation to CVD risk or have no association with CVD risk, some studies have raised concerns that egg consumption should be approached more cautiously in those at risk for diabetes $^{(24,27)}$. One meta-analysis found an increased risk of CHD associated with egg intake among diabetic patients (relative risk associated with one-egg increase $=1 \cdot 54 ; 95 \%$ CI 1.14, 2.09), but statistical power was limited in this subgroup due to a limited number of studies ${ }^{(25)}$. Another report examining six original studies of egg consumption and CVD risk in patients with or at risk for type 2 diabetes concluded that consumption of up to twelve eggs weekly had no effect on major CVD risk factors including TC, LDL-C, TAG, fasting glucose, insulin and C-reactive protein $^{(28)}$. Another review has pointed out that in most studies, egg consumption has had no negative effects on glycaemic control when tested in various populations including those who are obese or diabetic ${ }^{(29)}$. Therefore, more research is needed to clarify inconsistencies between studies, but there is currently insufficient evidence to support egg restriction among diabetics or those at risk for diabetes to reduce CVD risk $^{(30)}$.

One surprising finding of the present study was that egg consumption was positively associated with both BMI and WC. Several studies have suggested that eggs may actually be useful for weight management through promotion of satiety. In both children and adults it was shown that after an egg-based breakfast, people consumed significantly less energy later in the day than when consuming an isoenergetic grain-based breakfast such as cereal, oatmeal or bagels ${ }^{(31,32)}$. Multiple studies have also indicated that egg consumption at breakfast may reduce hunger during the rest of the day compared with a grain-based breakfast, assessed through both subjective measures of hunger and plasma grehlin ${ }^{(32-34)}$. Additionally, an analysis of weight changes over time in men and women from three large prospective cohort studies showed that egg consumption was not significantly associated with weight ${ }^{(35)}$. Therefore, the positive association noted in the present study of egg consumption with BMI and WC should be interpreted with caution given the strong existing evidence of eggs' potential usefulness in weight management. It is also possible that the association observed here between egg consumption and BMI is related to residual confounding that was not controlled for in the analysis. One study using NHANES 2001-2008 data found that egg consumers had higher WC and BMI than egg non-consumers; however, dietary pattern analysis revealed that this relationship was driven by a small subset of egg consumers whose dietary patterns were characterized by relatively high intakes of animal products and grains, suggesting that other foods consumed along with eggs may confound the relationship between eggs and $\mathrm{WC}$ or $\mathrm{BMI}^{(36)}$. Therefore, consideration should be given to total dietary patterns in addition to individual foods and/or nutrients, and additional studies are needed to better understand the relationships between egg consumption and various health markers.

In summary, the present study suggests that whole eggs contribute meaningfully to the nutritional quality of Americans' diets. Whole egg consumption appears to have no significant relationship with most of the CVD risk factors examined in the study, but egg consumption was associated with lower TAG, TC:HDL-C and TAG:HDL-C, all indicative of protection against CVD. However, egg consumption was also associated with higher BMI and WC, two indicators of increased CVD risk. Overall, the 
current literature on this topic contains mixed findings, but generally demonstrates no significant relationship between egg consumption on CVD risk, which supports the removal of the dietary cholesterol limitation in the most updated version of the Dietary Guidelines for Americans. The current study generally supports this revised dietary guidance. Importantly, the present study relies on cross-sectional survey data that are not suitable for determining causality between egg consumption and CVD risk markers. The study may also be limited due to self-reported dietary data collected on only two days as well as the inability to account for potential variability in nutrient composition of eggs based on the laying hens' diet or other factors ${ }^{(37)}$. Strengths of the current study include its use of several years of survey data from a nationally representative data source and its comprehensive examination of egg intake from both major and minor sources across all food groups in the FNDDS. Future research efforts should seek to clarify the mixed findings in the current literature regarding eggs and CVD risk markers through closer examination of populations that may be more sensitive to egg intake, such as hyperresponders to dietary cholesterol and those with genetic polymorphisms affecting cholesterol metabolism. Additionally, studies with long-term follow-up, careful control for confounding factors including lifestyle factors and other elements of individuals' dietary patterns, and with rigorous methods of dietary data collection will allow for better assessment of the relationship between eggs and CVD risk.

\section{Acknowledgements}

Financial support: This study was supported by the Allen Foundation (Principal Investigator: O.K.C.). The Allen Foundation had no role in the design, analysis or writing of this article. Conflict of interest: None. Authorship: O.K.C. designed the research; S.-J.C. performed statistical analyses; S.-J.C., M.M.M., M.L.F. and O.K.C. analysed and interpreted the data; M.M.M. wrote the paper. O.K.C. and M.M.M. had primary responsibility for the final content. All authors have read and approved the manuscript. Ethics of buman subject participation: Not applicable.

\section{References}

1. American Heart Association (2019) Heart Disease and Stroke Statistics - 2019: At-a-Glance. https://professional.heart.org/ idc/groups/ahamah-public/@wcm/@sop/@smd/documents/ downloadable/ucm_503396.pdf (accessed February 2019).

2. Nayor M \& Vasan RS (2016) Recent update to the US cholesterol treatment guidelines: a comparison with international guidelines. Circulation 133, 1795-1806.

3. US Department of Health and Human Services \& US Department of Agriculture (2015) 2015-2020 Dietary Guidelines for Americans, 8th ed. Washington, DC: US DHHS and USDA.
4. Kanter MM, Kris-Etherton PM, Fernandez ML et al. (2012) Exploring the factors that affect blood cholesterol and heart disease risk: is dietary cholesterol as bad for you as history leads us to believe? Adv Nutr 3, 711-717.

5. Berger S, Raman G, Vishwanathan R et al. (2015) Dietary cholesterol and cardiovascular disease: a systematic review. Am I Clin Nutr 102, 276-294.

6. Eckel RH (2015) Eggs and beyond: is dietary cholesterol no longer important? Am J Clin Nutr 102, 235-236.

7. Song WO \& Kerver JM (2000) Nutritional contribution of eggs to American diets. J Am Coll Nutr 19, 5 Suppl., $556 \mathrm{~S}-562 \mathrm{~S}$.

8. Conrad Z, Johnson LK, Roemmich JN et al. (2017) Time trends and patterns of reported egg consumption in the US by sociodemographic characteristics. Nutrients $\mathbf{9}$, E333.

9. Centers for Disease Control and Prevention, National Center for Health Statistics (year?) NHANES Response Rates and Population Totals. https://wwwn.cdc.gov/nchs/nhanes/ ResponseRates.aspx (accessed December 2018).

10. Ahluwalia N, Dwyer J, Terry A et al. (2016) Update on NHANES dietary data: focus on collection, release, analytical considerations, and uses to inform public policy. Adv Nutr 7, 121-134.

11. Institute of Medicine, Food and Nutrition Board (1998) Dietary Reference Intakes: A Risk Assessment Model for Establishing Upper Intake Levels for Nutrients. Washington, DC: National Academies Press.

12. Centers for Disease Control and Prevention, National Center for Health Statistics (2011) NHANES 2011-2012 Laboratory Methods. https://wwwn.cdc.gov/nchs/nhanes/continuousnhanes/ labmethods.aspx?BeginYear=2011 (accessed March 2018).

13. Krebs-Smith SM, Guenther PM, Subar AF et al. (2010) Americans do not meet federal dietary recommendations. $J$ Nutr 140, 1832-1838.

14. Moore LV, Dodd KW, Thompson FE et al. (2015) Using Behavioral Risk Factor Surveillance System data to estimate the percentage of the population meeting US Department of Agriculture food patterns fruit and vegetable intake recommendations. Am J Epidemiol 181, 979-988.

15. Phillips SM, Fulgoni VL 3rd, Heaney RP et al. (2015) Commonly consumed protein foods contribute to nutrient intake, diet quality, and nutrient adequacy. Am J Clin Nutr 101, 1346-1352.

16. Deshmukh-Taskar PR, Radcliffe JD, Liu Y et al. (2010) Do breakfast skipping and breakfast type affect energy intake, nutrient intake, nutrient adequacy, and diet quality in young adults? NHANES 1999-2002. J Am Coll Nutr 29, 407-418.

17. O'Neil CE, Nicklas TA \& Fulgoni VL (2014) Nutrient intake, diet quality, and weight/adiposity parameters in breakfast patterns compared with no breakfast in adults: National Health and Nutrition Examination Survey 2001-2008. J Acad Nutr Diet 114, 12 Suppl., S27-S43.

18. Penido MGMG \& Alon US (2012) Phosphate homeostasis and its role in bone health. Pediatr Nephrol 27, 2039-2048.

19. Mundy G \& Guise T (1999) Hormonal control of calcium homeostasis. Clin Chem 45, 1347-1352.

20. Johnson EJ (2014) Role of lutein and zeaxanthin in visual and cognitive function throughout the lifespan. Nutr Rev $\mathbf{7 2}$, 605-612.

21. Feeney J, O'Leary N, Moran R et al. (2017) Plasma lutein and zeaxanthin are associated with better cognitive function across multiple domains in a large population-based sample of older adults: findings from the Irish Longitudinal Study on Aging. J Gerontol Ser A 72, 1431-1436.

22. World Health Organization (2015) Guideline: Optimal Serum and Red Blood Cell Folate Concentrations in Women of Reproductive Age for Prevention of Neural Tube Defects. Geneva: WHO.

23. Geiker NRW, Lytken Larsen M, Dyerberg J et al. (2018) Egg consumption, cardiovascular diseases and type 2 diabetes. Eur J Clin Nutr 72, 44-56. 
24. Djoussé L \& Gaziano JM (2008) Egg consumption in relation to cardiovascular disease and mortality: the Physicians' Health Study. Am J Clin Nutr 87, 964-969.

25. Rong Y, Chen L, Zhu T et al. (2013) Egg consumption and risk of coronary heart disease and stroke: dose-response meta-analysis of prospective cohort studies. BMJ 346, e8539.

26. Xu L, Lam TH, Jiang CQ et al. (2018) Egg consumption and the risk of cardiovascular disease and all-cause mortality: Guangzhou Biobank Cohort Study and meta-analyses. Eur J Nutr. Published online: 21 April 2018. doi: 10.1007/s00394018-1692-3.

27. Hu FB, Stampfer MJ, Rimm EB et al. (1999) A prospective study of egg consumption and risk of cardiovascular disease in men and women. JAMA 281, 1387-1394.

28. Richard C, Cristall L, Fleming E et al. (2017) Impact of egg consumption on cardiovascular risk factors in individuals with type 2 diabetes and at risk for developing diabetes: a systematic review of randomized nutritional intervention studies. Can J Diabetes 41, 453-463.

29. Clayton ZS, Fusco E \& Kern M (2017) Egg consumption and heart health: a review. Nutrition 37, 79-85.

30. Fernandez ML \& Andersen CJ (2014) Effects of dietary cholesterol in diabetes and cardiovascular disease. Clin Lipidol 9, 607-616.
31. Kral TVE, Bannon AL, Chittams J et al. (2016) Comparison of the satiating properties of egg- versus cereal grain-based breakfasts for appetite and energy intake control in children. Eat Behav 20, 14-20.

32. Ratliff J, Leite JO, de Ogburn R et al. (2010) Consuming eggs for breakfast influences plasma glucose and ghrelin, while reducing energy intake during the next 24 hours in adult men. Nutr Res 30, 96-103.

33. Missimer A, Dimarco DM, Andersen CJ et al. (2017) Consuming two eggs per day, as compared to an oatmeal breakfast, increases plasma ghrelin while maintaining the LDL/HDL ratio. Nutrients 9 , E89.

34. Vander Wal JS, Khosla P, Jen KLC et al. (2005) Short-term effect of eggs on satiety in overweight and obese subjects. $J$ Am Coll Nutr 24, 510-515.

35. Smith JD, Hou T, Ludwig DS et al. (2015) Changes in intake of protein foods, carbohydrate amount and quality, and long-term weight change: results from 3 prospective cohorts. Am J Clin Nutr 101, 1216-1224.

36. Nicklas TA, O'Neil CE \& Fulgoni VL (2015) Differing statistical approaches affect the relation between egg consumption, adiposity, and cardiovascular risk factors in adults. $J$ Nutr 145, issue 1, 170S-176S.

37. Naber EC (1979) The effect of nutrition on the composition of eggs. Poult Sci 58, 518-528. 